\title{
Supracoronary ascending aortic replacement in patients with acute aortic dissection type A: What happens to the aortic root in the long run?
}

\author{
Bartosz Rylski, MD, ${ }^{\mathrm{a}}$ Friedhelm Beyersdorf, MD, PhD, ${ }^{\mathrm{a}}$ Philipp Blanke, MD, ${ }^{\mathrm{b}}$ Annika Boos, BS, \\ Isabell Hoffmann, $\mathrm{MD},{ }^{\mathrm{c}}$ Alexey Dashkevich, $\mathrm{MD},{ }^{\mathrm{a}}$ and Matthias Siepe, $\mathrm{MD}^{\mathrm{a}}$
}

Objective: Our objective was to determine long-term outcome predictors for patients with acute aortic dissection type A (AADA) and aortic root involvement.

\begin{abstract}
Methods: From 2001 through 2009, 119 of 152 patients operated on for AADA at a tertiary medical center underwent supracoronary ascending aortic replacement (52 women; mean age, $61 \pm 15$ years). Those with at least 1-year follow-up $(n=97)$ were retrospectively assessed for preoperative aortic root disease. Follow-up data were assessed for evidence of new-onset aortic root disease by computed tomography and echocardiography, and for reoperation for aortic root disease.
\end{abstract}

Results: Median follow-up was 33.8 months (range, 0-112 months). Twenty-six (27\%) patients had new-onset aortic root disease at $4.4 \pm 2.6$ years after the initial procedure (range, 1.0-8.2 years) and 10 required aortic root reoperation. Severe aortic dissection with extension to pelvic arteries was an independent predictor for newonset aortic root disease $(P<.01)$. Dissection of all aortic sinuses during the initial procedure was an independent predictor $(P<.05)$ for aortic root reoperation. Mean rate of aortic root expansion after supracoronary repair was $0.6 \pm 1.1 \mathrm{~mm}$ per year. Preoperative aortic root diameter and aortic sinus dissection did not affect survivals. Five-year survivals were similar in patients with and without new-onset aortic root disease $(91 \%$ vs $89 \%$; $P=.79)$.

Conclusions: In patients with AADA, dissection of 3 aortic sinuses is an independent predictor for need of reoperation, whereas dissection extension into the iliac arteries is a predictor of secondary aortic root disease. Long-term follow-up at close intervals is warranted in patients with supracoronary ascending aortic replacement to reduce mortality caused by new onset of aortic root disease. (J Thorac Cardiovasc Surg 2013;146:285-90)

Acute aortic dissection type A (AADA) remains a lifethreatening disease. ${ }^{1,2}$ First-line therapy usually comprises emergency surgery aiming at preserving life with the lowest perioperative risk profile possible. Therefore, supracoronary ascending aortic replacement constitutes the most common surgical procedure for AADA. ${ }^{2-5}$

Complete resection of the intimal tear and prosthetic replacement of the ascending aorta with reapproximation of the proximal and distal edges are considered standard in AADA surgery. In patients with severe disruption of the sinus of Valsalva and with an aortic sinus diameter greater than $50 \mathrm{~mm}$ or severe aortic insufficiency, more extensive

\footnotetext{
From the Heart Center Freiburg University, ${ }^{\text {a }}$ Freiburg, the Department of Diagnostic Radiology, ${ }^{\mathrm{b}}$ University Hospital Freiburg, and the Institute for Medical Biostatistics, ${ }^{\mathrm{c}}$ Epidemiology and Informatics, Medical Center of Johannes Gutenberg-University, Mainz, Germany.

Disclosures: Authors have nothing to disclose with regard to commercial support.

Received for publication Feb 19, 2012; revisions received June 11, 2012; accepted for publication July 10, 2012; available ahead of print July 30, 2012

Address for reprints: Bartosz Rylski, MD, Heart Center Freiburg University,

Hugstetter Strasse 55, 79106 Freiburg, Germany (E-mail: bartosz.rylski@

universitaets-herzzentrum.de).

$0022-5223 / \$ 36.00$

Copyright (c) 2013 by The American Association for Thoracic Surgery

http://dx.doi.org/10.1016/j.jtcvs.2012.07.013
}

surgery with aortic root replacement is warranted. However, the surgical strategy for patients with moderate aortic root involvement remains controversial, especially in those with serious perioperative risk owing to advanced age or comorbidities. It remains unknown whether ascending aortic replacement with no or reconstructive surgery of the aortic root predisposes patients with AADA who have moderate aortic root involvement to new-onset aortic root disease and a need for reoperation in the late postoperative period.

Therefore, we sought to investigate risk factors of new-onset aortic root disease with and without the need for reoperation in patients with AADA who underwent supracoronary ascending aortic replacement.

\section{METHODS \\ Patient Population}

This retrospective study was approved by the institutional review board. The need for informed consent was waived. From 2001 through 2009, 152 patients (52 women; mean age, $61 \pm 15$ years) with AADA underwent emergency surgery at our institution. Of the 119 patients who underwent supracoronary aortic replacement, $7(6 \%)$ were lost to follow-up after discharge, $9(8 \%)$ patients died within 30 days after surgery, and 6 patients died within 1 year after surgery. Thus 97 patients with supracoronary aortic replacement and at least 1 year of follow-up comprised our final study population. Five $(4 \%)$ patients received a diagnosis of Marfan syndrome 


\section{Abbreviations and Acronyms \\ AADA $=$ acute aortic dissection type A \\ $\mathrm{CT}=$ computed tomography}

postoperatively. These patients were included into the analysis. Descriptive characteristics of the study population are presented in Table 1.

\section{Surgical Management}

According to our institutional policies, surgery on the ascending aorta was limited to supracoronary aortic replacement in patients with normal aortic root diameters, absent or mild aortic insufficiency, and no known genetic connective tissue disorders. In patients with moderate aortic root involvement (defined as aortic root diameter of $40-49 \mathrm{~mm}$ or with dissection of the aortic sinus wall), the surgical regimen was a case-to-case decision. In patients with sinus dissection we routinely use BioGlue (CryoLife Inc, Kennesaw, Ga) to seal dissected layers of the aorta. Fourteen patients underwent hemiarch replacement and 7 total arch replacement.

\section{Aortic Root Dimension and Extent of Dissection}

Aortic root dimensions were assessed by computed tomography (CT) data sets using multiplanar reformatted reconstructions. To assess the aortic sinus dimensions, we took caliper measurements from each sinus to the opposing commissure and then averaged them. The extent of dissection into the 3 sinuses was noted from CT images and surgical reports.

\section{Patient Follow-up}

Retrospective analysis comprised patient data obtained from our institutional database, including inpatient and outpatient data. Data obtained until April 2011 were included in the analysis. In addition, for patients not undergoing follow-up at our institution, the primary care physician was contacted and imaging data retrieved.

The follow-up protocol included postoperative CT angiography before discharge, clinical examination and CT angiography 6 and 12 months postoperatively, and annually thereafter according to current guidelines. ${ }^{6}$ Median follow-up was 33.8 months (interquartile range, $0-112$ months). Thirty-two of 97 patients underwent the primary aortic operation within the last 5 years of data inclusion. Thus 5-year survival data were available for 65 of 97 patients.

\section{Study End Points}

Our primary end points were new-onset aortic root disease or reoperation for aortic root disease. New-onset aortic root disease was defined as mean growth rate of the aortic root greater than $2 \mathrm{~mm}$ per year, suture aneurysm, severe aortic valve insufficiency, or recurrent dissection of aortic sinus.

\section{Statistical Analysis}

Statistics were summarized as the frequency and percentage for categorical variables and the mean and standard deviation for continuous variables. The influences of different variables (listed in Tables 1 and 2) on new-onset aortic root disease were analyzed separately by logistic regression. Logistic regression was performed for each variable, adjusting for age and sex in each case. Age and gender were separately analyzed using univariate regression analysis. The same analysis was used to test for influence of different disturbance variables (see Table 2) on reoperation on the aortic root. Kaplan-Meier curves were calculated for survival of all patients and for survival of those with and without new-onset aortic root disease. Survival was defined as time from the operation date to the date of death or to June 15 of the year in which the observation stopped. A log-rank test was estimated to compare survival times between patients with and without newonset aortic root disease. Because this is an explorative study, the term "statistically significant" should be interpreted with care. There was no formal adjustment for the number of performed tests. Analysis was performed with SAS software, version 9.2 (SAS Institute, Inc, Cary, NC).

\section{RESULTS \\ Survival}

Overall 5-year survival was $89.2 \%(58 / 65)$ and influenced by neither preoperative aortic root diameter nor aortic sinus dissection. Survivals for patients with and without new-onset aortic root disease were $91 \%$ versus $89 \%$ at 5 years $(P=.79)$. Kaplan-Meier estimates of survival for all patients and for those having new-onset aortic root disease are illustrated in Figure 1, $A$ and $B$, respectively.

\section{New-Onset Aortic Root Disease}

During the study period, $26(27 \%)$ patients showed evidence of new-onset aortic root disease: aortic root expansion in $15(13 \%)$, suture aneurysm in $6(5 \%)$, recurrent dissection in $3(3 \%)$, and aortic valve insufficiency in 3 (3\%) patients. New-onset aortic root disease was diagnosed within $4.4 \pm 2.6$ years after the initial procedure (range, 1.0 8.2 years). We observed a correlation between severe aortic dissection with extension to iliac arteries and new-onset aortic root disease (odds ratio, 3.57; 95\% confidence interval, 1.36-9.35; $P<.01)$. However, no association was found between age, gender, dissection of all aortic sinuses, and new-onset aortic root disease (Table 2).

Patients with new-onset aortic root disease revealed a more extensive pattern of aortic initial dissection with more frequent extension of dissection to supra-aortic vessels $(35 \%$ vs $30 \% ; P=.8)$, the infradiaphragmal aorta $(62 \%$ vs $41 \% ; P=.12)$, and a significantly higher frequency of dissection into the iliac arteries $(54 \%$ vs $24 \% ; P=.01)$ when compared with patients without evidence of new-onset aortic root disease. Mean rate of aortic root dilation was $0.6 \pm$ $1.1 \mathrm{~mm}$ per year in the entire study cohort. Dissection and procedural characteristics of patients with and without new-onset aortic root disorder are listed in Table 1.

\section{Aortic Root Reoperation}

Of the 26 patients with a new-onset aortic root disorder, 10 required aortic root reoperation at a mean interval of $5.4 \pm 3.3$ years after the initial procedure (range, 0.6-9.2 years). Reoperation was performed in 7 patients electively and in 3 with urgency. Indications for reoperation were severe aortic valve insufficiency $(n=4)$, suture aneurysm $(\mathrm{n}=2)$, severe aortic valve insufficiency and suture aneurysm $(n=3)$, and dilatation of the sinus of Valsalva with aortic valve insufficiency $(\mathrm{n}=1)$. Of the 10 patients who underwent aortic root reoperation, 1 died in the hospital of multiple organ dysfunction syndrome and another after 2 months of a suture aneurysm on the proximal aorta, which led to cardiac insufficiency and sepsis. Patient characteristics are listed in Tables 3 and 4. 
TABLE 1. Demographics, clinical and dissection characteristics, and follow-up aortic root structure for the entire cohort and for patients with and without new-onset aortic root disease

\begin{tabular}{|c|c|c|c|c|}
\hline & $\begin{array}{c}\text { All } \\
(\mathbf{n}=\mathbf{9 7})\end{array}$ & $\begin{array}{l}\text { New-onset aortic root disease } \\
(n=26)\end{array}$ & $\begin{array}{l}\text { No new-onset aortic root disease } \\
((n=71)\end{array}$ & $\begin{array}{c}P \\
\text { value } \\
\end{array}$ \\
\hline \multicolumn{5}{|l|}{ Demographics } \\
\hline Age, y & $61.2 \pm 13.8$ & $59.2 \pm 13.4$ & $62.0 \pm 14.0$ & .37 \\
\hline Female, n (\%) & $32(33.0)$ & $8(30.8)$ & $24(33.8)$ & .78 \\
\hline \multicolumn{5}{|l|}{ Clinical presentation, $\mathrm{n}(\%)$} \\
\hline Hypertension & $85(87.6)$ & $24(92.3)$ & $61(85.9)$ & .33 \\
\hline Marfan syndrome & $5(5.2)$ & $1(3.9)$ & $4(5.6)$ & .53 \\
\hline Previous cardiac surgery & $4(4.1)$ & $1(3.9)$ & $3(4.2)$ & \\
\hline Bicuspid aortic valve & 0 & $1(3.9)$ & $1(1.0)$ & .99 \\
\hline Iatrogenic dissection & $4(4.1)$ & $1(3.9)$ & $3(4.2)$ & .94 \\
\hline Shock & $8(8.3)$ & $3(11.5)$ & $5(7.0)$ & .48 \\
\hline \multicolumn{5}{|l|}{ Malperfusion } \\
\hline Neurologic & $16(16.5)$ & $5(19.2)$ & $11(15.5)$ & .68 \\
\hline Cardiac & $5(5.2)$ & $1(3.9)$ & $4(5.6)$ & .59 \\
\hline Visceral & $4(4.1)$ & 0 & $4(5.6)$ & .98 \\
\hline Peripheral & $6(6.2)$ & $1(3.9)$ & $5(7.0)$ & .55 \\
\hline \multicolumn{5}{|l|}{ Involvement of aortic dissection, $\mathrm{n}(\%)$} \\
\hline Aortic arch & $67(69.1)$ & $21(80.8)$ & $46(64.8)$ & .23 \\
\hline Supra-aortic vessels & $30(30.9)$ & $9(34.6)$ & $21(29.6)$ & .77 \\
\hline Descending thoracic aorta & $51(52.6)$ & $18(69.2)$ & $33(46.5)$ & .08 \\
\hline Descending abdominal aorta & $45(46.4)$ & $16(61.5)$ & $29(40.8)$ & .12 \\
\hline Iliac vessels & $31(32.0)$ & $14(53.9)$ & $17(23.9)$ & .01 \\
\hline \multicolumn{5}{|l|}{ Aortic root at presentation } \\
\hline Diameter, mm & $41.7 \pm 5.8$ & $42.0 \pm 5.9$ & $41.6 \pm 5.9$ & .75 \\
\hline Severe aortic valve regurgitation, $\mathrm{n}(\%)$ & $10(10.3)$ & $4(15.4)$ & $6(8.5)$ & .37 \\
\hline Dissection of 3 sinuses, $\mathrm{n}(\%)$ & $32(33.0)$ & $10(38.5)$ & $22(31.0)$ & .35 \\
\hline \multicolumn{5}{|l|}{ Surgical management } \\
\hline ECC time, min & $181.7 \pm 48.3$ & $182.1 \pm 46.9$ & $181.6 \pm 49.1$ & .99 \\
\hline Aortic crossclamp time, min & $83.4 \pm 30.1$ & $82.7 \pm 32.7$ & $83.7 \pm 29.4$ & .66 \\
\hline Antegrade cerebral perfusion time, $\min$ & $27.8 \pm 21.0$ & $21.8 \pm 15.6$ & $29.9 \pm 22.4$ & .18 \\
\hline \multicolumn{5}{|l|}{ Sinus of Valsalva dimensions on follow-up CT } \\
\hline Diameter, mm & $41.8 \pm 6.3$ & $46.0 \pm 7.4$ & $40.2 \pm 5.0$ & .0003 \\
\hline Growth rate, $\mathrm{mm} / \mathrm{y}$ & $0.6 \pm 1.1$ & $1.3 \pm 1.3$ & $0.2 \pm 0.7$ & .02 \\
\hline \multicolumn{5}{|l|}{ Outcome, n (\%) } \\
\hline Five-year survival & $58 / 65(89.2)$ & 19/21 (90.5) & $39 / 44(88.6)$ & .79 \\
\hline
\end{tabular}

Differences between both groups were evaluated using regression analysis adjusted for age and gender. The influence of age and gender on incidence of new-onset aortic root disease was calculated by univariate regression analysis. ECC, Extracorporeal circulation; $C T$, computed tomography.

Multivariate analysis revealed dissection of all aortic sinuses at the time of the initial procedure as an independent predictor $(P<.05)$ of aortic root reoperation. Neither aortic valve regurgitation nor aortic root diameter predicted the need for aortic root reoperation (Table 2). Kaplan-Meier estimate of freedom from reoperation in patients after supracoronary ascending replacement is shown in Figure 1, $C$.

\section{DISCUSSION}

To minimize the perioperative risk in patients with AADA, surgeons may choose to limit the extent of surgery involving supracoronary ascending aortic replacement with valve resuspension. ${ }^{2}$ An alternative is more aggressive, involving aortic root replacement using a composite graft or a valve-sparing procedure. Although the more extensive surgery may be associated with higher perioperative risk, it eliminates the risk of future aneurysmal dilatation and redissection of the aortic root or aortic valve incompetence. ${ }^{7,8}$ However, the risk of proximal false aneurysm and infection requiring redo surgery remains. ${ }^{9}$ Inasmuch as the optimal surgical regimen for patients with AADA who have moderate aortic root involvement is not yet established, we sought to analyze our experience in patients who underwent a limited surgical approach and supracoronary replacement to identify predictive factors for unfavorable outcome.

\section{Survival}

Advances in diagnostic modalities and refinements in surgical strategies have improved AADA surgery outcomes over the past decade. ${ }^{10,11}$ Published data from the International Registry of Acute Aortic Dissection reported 
TABLE 2. Analysis of risk factors for new-onset aortic root disease and reoperation

\begin{tabular}{|c|c|c|c|c|c|c|}
\hline \multirow[b]{2}{*}{$\begin{array}{c}\text { Risk } \\
\text { factors }\end{array}$} & \multicolumn{3}{|c|}{$\begin{array}{c}\text { New-onset } \\
\text { aortic root disease }\end{array}$} & \multicolumn{3}{|c|}{$\begin{array}{c}\text { Reoperation on } \\
\text { the aortic root }\end{array}$} \\
\hline & OR & $95 \% \mathrm{CI}$ & $\begin{array}{c}P \\
\text { value }\end{array}$ & OR & $95 \%$ CI & $\begin{array}{c}P \\
\text { value }\end{array}$ \\
\hline Age & 0.98 & $0.95-1.02$ & .33 & 0.99 & $0.95-1.04$ & .66 \\
\hline Gender & 1.06 & $0.38-2.95$ & .91 & 0.45 & $0.12-1.69$ & .24 \\
\hline Aortic root diameter & 1.02 & $0.93-1.11$ & .75 & 1.05 & $0.92-1.20$ & .48 \\
\hline $\begin{array}{c}\text { Dissection of all } \\
\text { aortic sinuses }\end{array}$ & 1.28 & $0.49-3.37$ & .62 & 6.01 & $1.34-26.9$ & $<.05$ \\
\hline $\begin{array}{l}\text { Severe aortic valve } \\
\text { regurgitation }\end{array}$ & 1.90 & $0.48-7.56$ & .37 & 1.21 & $0.13-11.4$ & .87 \\
\hline $\begin{array}{l}\text { Dissection extension } \\
\text { to pelvic arteries }\end{array}$ & 3.57 & $1.36-9.35$ & $<.01$ & 1.65 & $0.41-6.64$ & .48 \\
\hline
\end{tabular}

Age and gender were analyzed univariately, and aortic root diameter, dissection of aortic sinuses, and severe aortic valve regurgitation were analyzed multivariately according to age and gender. $O R$, Odds ratio; $C I$, confidence interval.

an in-hospital mortality rate of $26 \%$ after surgical repair in patients enrolled to the registry between 1996 and $1998 .^{12}$ The latest report from the German Registry of Aortic Dissection Type A describes a 30-day mortality rate of $17 \%$ in patients treated between 2006 and 2009. ${ }^{13}$ Despite these advances, AADA remains a catastrophic event associated with a high hospital mortality rate and significant postoperative morbidity in survivors. Encouragingly, the in-hospital mortality in our series of patients with supracoronary ascending aortic replacement is very low $(8 \%)$ even though we tend to perform this type of operation in older patients. Five-year survival was similar in patients with and without new-onset aortic root disease. Those with new-onset aortic root disease were scheduled to a follow-up protocol at closer intervals (3-6 months), which enabled us to operate on them early enough to prevent further serious complications that might have proved fatal. These findings highlight the need for annual aortic imaging by CT or magnetic resonance as recommended in the latest guidelines for the management of patients with thoracic aortic disease. ${ }^{6}$

\section{New-Onset Aortic Root Disease}

During the follow-up, CT revealed various aortic root diseases, the most common being progressive dilatation of the remaining native aorta. In our series, the average growth rate of the sinus of Valsalva's diameter was $0.6 \mathrm{~mm}$ per year. Whenever a tendency to root enlargement is diagnosed, one must shorten the interval for the next diagnostic imaging examination to 6 or even 3 months. According to Kobuch and associates, ${ }^{14}$ the native aorta's dimensions may remain constant for years and then suddenly increase for unknown reason(s), perhaps an effect of hypertonic episodes. Our cohort's second most common aortic pathologic condition was suture aneurysm. It is a rare but serious and complex complication usually requiring surgical repair. $\mathrm{Pa}-$ tients with aortic dissection show a high incidence of suture
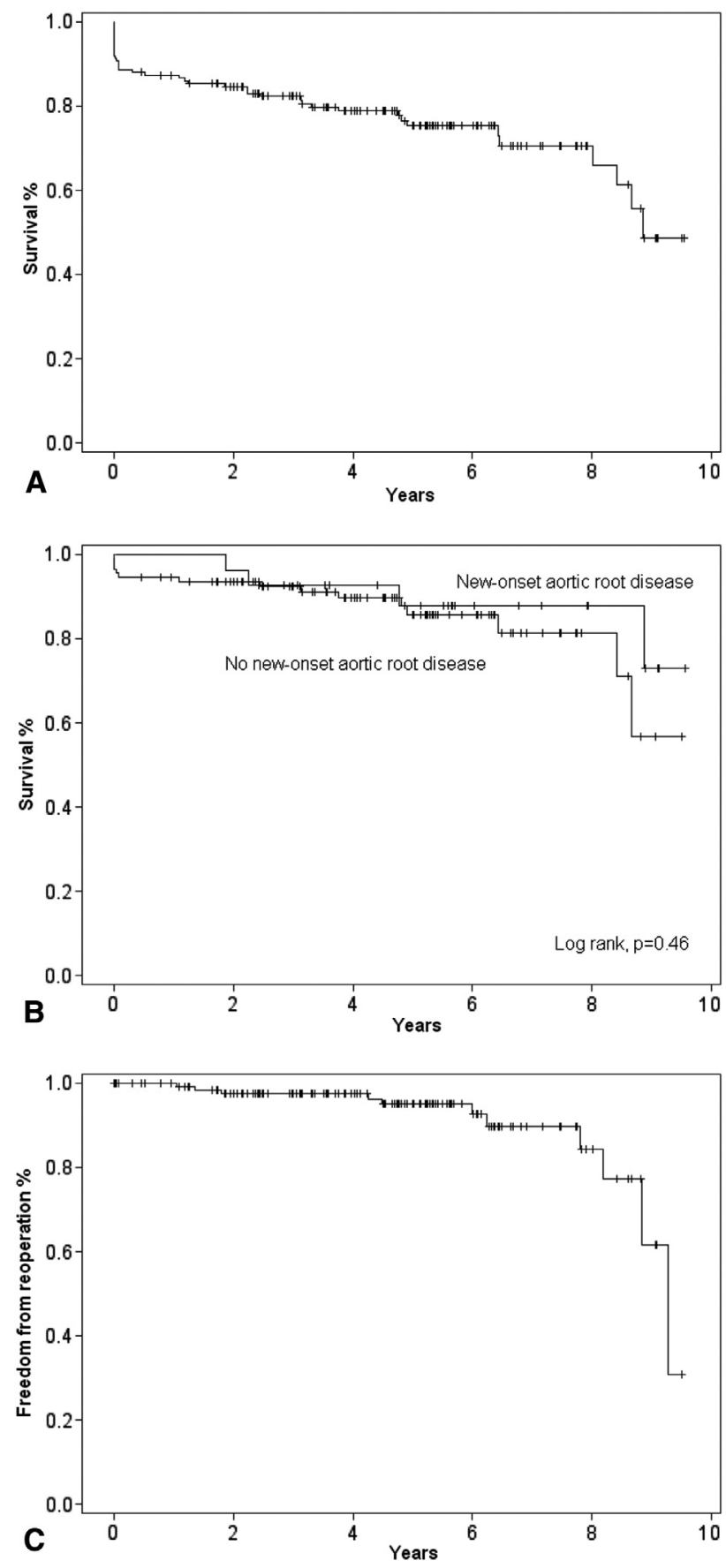

FIGURE 1. Kaplan-Meier estimates of survival for the entire cohort (A) and for patients with new-onset aortic root disease (B) and freedom from reoperation $(\mathrm{C})$.

aneurysm, probably owing to increased tissue fragility in the suture line. However, this complication is not limited to patients with AADA. Suture aneurysm and subsequent suture line rupture are widely known from surgery on the ascending aorta. ${ }^{15-18}$ Residual dissection and progressive aortic valve incompetence were equally frequent in our patients. 
TABLE 3. Demographics and indication for redo surgery

\begin{tabular}{|c|c|c|c|c|c|c|}
\hline Patients & Age, $y$ & $\begin{array}{l}\text { Time between initial and } \\
\text { secondary procedure, } y\end{array}$ & $\begin{array}{c}\text { Sinus Valsalva } \\
\text { diameter, } \mathbf{m m}\end{array}$ & $\begin{array}{c}\text { Severe aortic valve } \\
\text { insufficiency }\end{array}$ & $\begin{array}{c}\text { Suture } \\
\text { aneurysm }\end{array}$ & $\begin{array}{l}\text { Priority of } \\
\text { procedure } \\
\end{array}$ \\
\hline 1 & 79 & 1.8 & 44 & 1 & 0 & Elective \\
\hline 2 & 62 & 9.3 & 67 & 1 & 0 & Elective \\
\hline 3 & 74 & 8.8 & 44 & 1 & 1 & Urgent \\
\hline 4 & 80 & 7.8 & 38 & 0 & 1 & Urgent \\
\hline 5 & 55 & 4.3 & 42 & 1 & 0 & Urgent \\
\hline 6 & 55 & 8.2 & 38 & 1 & 1 & Elective \\
\hline 7 & 75 & 6.3 & 45 & 0 & 1 & Elective \\
\hline 8 & 70 & 1.3 & 47 & 1 & 0 & Elective \\
\hline 9 & 30 & 6.0 & 48 & 1 & 0 & Elective \\
\hline 10 & 67 & 4.5 & 38 & 1 & 1 & Elective \\
\hline
\end{tabular}

We are the first to demonstrate that dissection of the entire aorta at the time of the initial procedure constitutes a risk factor for aortic root complications in the long run. Dissection of the entire aorta extending to the aortic branches suggests generalized aortic tissue vulnerability in these patients. Thus both aortic root involvement and the extent of antegrade dissection demand consideration in patients with AADA when determining the surgical strategy.

More than a quarter of patients investigated in this study received a diagnosis of new-onset aortic root disease, underlining the general importance of this entity. The average time interval between the initial procedure and occurrence of aortic root disorder was 4 years. These findings demonstrate convincingly that long-term follow-up is mandatory, as recommended by current guidelines. ${ }^{6}$

\section{Reoperation on Aortic Root}

In this series, almost half of the patients identified with new-onset aortic root disease required reoperation. Our $10 \%$ reoperation rate among all patients with supracoronary aortic replacement resembles that in previous reports. ${ }^{14,19}$ Although all reoperations took place without significant procedural difficulties and revealed an acceptable in-hospital mortality rate, the postoperative course was rather long and involved extensive resource use.
Previously reported predisposing factors for conditions requiring reoperation are incomplete excision of the tear, failure to obliterate the false lumen, and severe aortic valve regurgitation. ${ }^{20-22}$ In our series we also demonstrate that patients with dissection of all aortic sinuses carry an increased risk for reoperation on the aortic root after conservative proximal repair. Importantly, dissection of just 1 or 2 sinuses was safely repaired using reconstruction and supracoronary replacement without showing an increased risk of new-onset root disease. Thus established risk factors for new-onset aortic root disease and reoperation must be considered whenever deciding between a limited or more aggressive surgical approach in patients with AADA who have moderate aortic root involvement.

We found no association between age at the time of dissection and new-onset aortic root disease or reoperation on the aortic root. However, given the "relatively" short median follow-up period of 33.8 months, larger studies with longer follow-up data in young patients are warranted to provide more insights into the role of age at the time of dissection and long-term outcome.

\section{CONCLUSIONS}

Patients with AADA who undergo supracoronary ascending aortic replacement carry a high risk of late aortic root

TABLE 4. Resource use and outcome in patients who underwent redo surgery

\begin{tabular}{|c|c|c|c|c|c|c|c|}
\hline Patients & $\begin{array}{c}\text { Revision for } \\
\text { bleeding } \\
\end{array}$ & Ventilation, $\mathbf{h}$ & $\begin{array}{c}\text { Cerebrovascular } \\
\text { accident }\end{array}$ & ICU stay, d & $\begin{array}{c}\text { Hospital } \\
\text { stay, d }\end{array}$ & $\begin{array}{c}\text { In-hospital } \\
\text { mortality }\end{array}$ & $\begin{array}{l}\text { One-year } \\
\text { mortality } \\
\end{array}$ \\
\hline 1 & 0 & 96 & 1 & 11 & 27 & 0 & 0 \\
\hline 2 & 0 & 24 & 0 & 3 & 17 & 0 & 1 \\
\hline 3 & 1 & 190 & 0 & 8 & 8 & 1 & 1 \\
\hline 4 & 0 & 20 & 0 & 2 & 20 & 0 & 0 \\
\hline 5 & 0 & 21 & 0 & 2 & 21 & 0 & 0 \\
\hline 6 & 0 & 28 & 0 & 3 & 10 & 0 & 0 \\
\hline 7 & 0 & 118 & 0 & 11 & 21 & 0 & 0 \\
\hline 8 & 0 & 6 & 0 & 2 & 14 & 0 & 0 \\
\hline 9 & 1 & 44 & 0 & 4 & 49 & 0 & 0 \\
\hline 10 & 0 & 6 & 0 & 2 & 9 & 0 & 0 \\
\hline
\end{tabular}

$I C U$, Intensive care unit. 
reoperation. According to the data from this monocentric investigation, dissection of 3 aortic sinuses is an independent predictor for need of reoperation, whereas dissection extension into the iliac arteries is a predictor of secondary aortic root disease. These risk factors must be considered when opting for a surgical approach limited to ascending aortic replacement and warrant close long-term follow up with cross-sectional imaging.

\section{References}

1. Mehta RH, Suzuki T, Hagan PG, Bosson E, Gilon D, Llovet A, et al. Predicting inhospital mortality in acute type A aortic dissection. Circulation. 2002;105:200-6.

2. Rylski B, Suedkamp M, Beyersdorf F, Nitsch B, Hoffmann I, Blettner M, et al. Outcome after surgery for acute aortic dissection type A in patients over 70 years: data analysis from the German Registry for Acute Aortic Dissection Type A (GERAADA). Eur J Cardiothorac Surg. 2011;40:435-40.

3. Moon MR, Sundt TM, Pasque MK, Barner HB, Huddleston CB, Damianot RJ, et al. Does the extent of proximal or distal resection influence outcome for type A dissections? Ann Thorac Surg. 2001;71:1244-9.

4. Kim JB, Chung CH, Moon DH, Ha GJ, Lee TY, Jung SH, et al. Total arch repair versus hemiarch repair in the management of acute DeBakey type I aortic dissection. Eur J Cardiothorac Surg. 2011;40:881-7.

5. Pugliese P, Pessotto R, Santini F, Montalbano G, Luciani GB, Mazzucco A. Risk of late reoparations in patients with acute type A aortic dissection: impact of a more radical surgical approach. Eur J Cardiothorac Surg. 1998;13:576-81.

6. Hiratzka LF, Bakris GL, Beckman JA, Bersin RM, Carr VF, Casey DE, et al. 2010 ACCF/AHA/AATS/ACR/ASA/SCA/SCAI/SIR/STS/SVM guidelines for the diagnosis and management of patients with thoracic aortic disease: a report of the American College of Cardiology Foundation/American Heart Association Task Force on Practice Guidelines, American Association for Thoracic Surgery, American College of Radiology, American Stroke Association, Society of Cardiovascular Anesthesiologists, Society for Cardiovascular Angiography and Interventions, Society of Interventional Radiology, Society of Thoracic Surgeons, and Society for Vascular Medicine. Circulation. 2010;121:e266-369.

7. Ergin MA, McCullough J, Galla JD, Lansman SL, Griepp RB. Radical replacement of the aortic root in acute type A dissection: indications and outcome. Eur J Cardiothorac Surg. 1996;10:840-5.

8. Halstead JC, Spielvogel D, Meier DM, Rinke S, Bodian C, Malekan R, et al. Composite aortic root replacement in acute type A dissection: time to rethink the indications? Eur J Cardiothorac Surg. 2005;27:626-32.
9. Estrera AL, Miller CC, Villa MA, Lee TY, Meada R, Irani A, et al. Proximal reoperations after repaired acute type A aortic dissection. Ann Thorac Surg. 2007; 83:1603-8.

10. Rylski B, Siepe M, Schoellhorn J, Beyersdorf F. An improved technique for aortic anastomosis: graft telescopic inversion. J Thorac Cardiovasc Surg. 2010;140: 934-5.

11. Rylski B, Siepe M, Blanke P, Euringer W, Schoellhorn J, Beyersdorf F. Adventitial inversion with graft telescopic insertion for distal anastomosis in acute type A aortic dissection. Ann Thorac Cardiovasc Surg. 2012;18: 278-80.

12. Hagan PG, Nienaber CA, Isselbacher EM, Bruckman D, Karavite DJ, Russman PL, et al. The International Registry of Acute Aortic Dissection (IRAD): new insights into an old disease. JAMA. 2000;283:897-903.

13. Conzelmann LO, Krüger T, Hoffmann I, Rylski B, Easo J, Oezkur M, et al. German Registry for Acute Aortic Dissection Type A (GERAADA): initial results. Herz. 2011;36:513-24.

14. Kobuch R, Hilker M, Rupprecht L, Hirt S, Keyser A, Puehler T, et al. Late reoperations after repaired acute type A aortic dissection. J Thorac Cardiovasc Surg. 2011 Nov 11 [Epub ahead of print]

15. Katsumata T, Moorjani N, Vaccari G, Westaby S. Mediastinal false aneurysm after thoracic aortic surgery. Ann Thorac Surg. 2000;70:547-52.

16. Mohammadi S, Bonnet N, Leprince P, Kolsi M, Rama A, Pavie A, et al. Reoperation for false aneurysm of the ascending aorta after its prosthetic replacement: surgical strategy. Ann Thorac Surg. 2005;79:147-52.

17. Garisto JD, Medina A, Williams DB, Carrillo RG. Surgical management of a giant ascending aortic pseudoaneurysm. Tex Heart Inst J. 2010;37:710-3.

18. Di Eusanio M, Berretta P, Bissoni L, Petridis FD, Di Marco L, Di Bartolomeo R. Re-operations on the proximal thoracic aorta: results and predictors of short- and long-term mortality in a series of 174 patients. Eur J Cardiothorac Surg. 2011;40: 1072-6.

19. Geirsson A, Bavaria JE, Swarr D, Keane MG, Woo YJ, Szeto WY. Fate of the residual distal and proximal aorta after acute type a dissection repair using a contemporary surgical reconstruction algorithm. Ann Thorac Surg. 2007;84: 1955-64.

20. Kirsch M, Soustelle C, Houël R, Hillion ML, Loisance D. Risk factor analysis for proximal and distal reoperations after surgery for acute type A aortic dissection. $J$ Thorac Cardiovasc Surg. 2002;123:318-25.

21. Westaby S, Saito S, Katsumata T. Acute type A dissection: conservative methods provide consistently low mortality. Ann Thorac Surg. 2002;73: 707-13.

22. Pessotto R, Santini F, Pugliese P, Montalbano G, Luciani GB, Faggian G. Preservation of the aortic valve in acute type A dissection complicated by aortic regurgitation. Ann Thorac Surg. 1999;67:2010-3. 